www.jmscr.igmpublication.org

Impact Factor (SJIF): 6.379

Index Copernicus Value: 79.54

ISSN (e)-2347-176x ISSN (p) 2455-0450

crossrefDOI: https://dx.doi.org/10.18535/jmscr/v6i10.32

\title{
Dexmedetomidine and Clonidine as an Adjuvant to Ropivacaine for Epidural Anaesthesia
}

\author{
Authors \\ Gullapalli Hanumantharao $^{1}$, G. Bharathi ${ }^{2}$, K. Nagarjuna Reddy ${ }^{3}$ \\ ${ }^{1,2}$ Associate Professor, Dept of Anaesthesiology, MGM Hospital, Kakatiya Medical College, Warangal, \\ Telangana State, India \\ ${ }^{3}$ Professor and Head, Dept of Anaesthesiology, MGM Hospital, Kakatiya Medical College, Warangal, \\ Telangana State, India \\ Corresponding Author \\ G. Bharathi
}

Email: Dr.gbharathi.kmcwgl@gmail.com, Mobile no: 9866486733

\begin{abstract}
Regional Anaesthesia is an excellent choice which provides effective intra \& post-operative analgesia with a single technique which is being possible due to the availability of long acting amide local anaesthetics like Ropivacaine and by the addition of adjuvants like clonidine and Dexmedetomidine. In our study we compared the effects of Clonidine $(2 \mathrm{mcg} / \mathrm{kg})$ with Dexmedetomidine $(1.5 \mathrm{mcg} / \mathrm{kg})$ as an adjunct to Epidural $0.75 \%$ Ropivacaine in lower abdominal and lower limb surgeries in adult patients. The mean time of onset of sensory blockade and mean time of onset of motor blockade in Dexmedetomidine group is significantly less than Clonidine group. The 2 segment regression time, The mean duration of sensory blockade and mean duration of motor blockade was significantly higher with Dexmedetomidine group than Clonidine group. The duration of analgesia was significantly prolonged and highest in the Dexmedetomidine group compared to Clonidine group. Both groups were similar in haemodynamic stability. We conclude that dexmedetomidine is a better adjuvant than clonidine in epidural anaesthesia as far as patient comfort, stable cardio-respiratory parameters, intra-operative and post-operative analgesia is concerned.
\end{abstract}

Keywords: Dexmedetomidine, Ropivacaine, Clonidine, Epidural, Regional Anaesthesia, Haemodynamics.

\section{Introduction}

Regional anesthesia is currently the most effective method of reducing the stress response especially in patients with surgical procedures involving the lower part of the body. In view of the wider application of regional anesthetic procedure in modern anesthesia practice, there is a need for local anesthetic with desirable properties like longer duration of sensory blockade and lesser duration of motor paralysis. Surgical methods and the anaesthetic techniques have evolved and improved drastically over the last two decades. Many techniques and drug regimens, with partial or greater success, have been tried from time to time to calm the patients and to eliminate the anxiety component during regional anaesthesia ${ }^{[1,2]}$.

The fear of surgery, the strange surroundings of the operation theatre, the sight and sound of 
sophisticated equipment, dynamicity of an 'operation' during regional anaesthesia and the masked faces of so many strange personale makes the patient panic to any extent ${ }^{[3]}$. The intense sensory and motor block, continuous supine position for a prolonged duration and the inability to move the body during regional anaesthesia brings a feeling of discomfort and phobia in many of the patients $^{[4]}$.

Adjuvant agents are pharmacological drugs that, when co-administered with local anaesthetic agents, may improve the speed of onset, the quality and / or duration of analgesia with desirable sedation. A wide range of drugs has been assessed for both neuraxial and peripheral nerve blocks. $\alpha-2$ adrenergic agonists have both analgesic and sedative properties when used as an adjuvant in regional anaesthesia ${ }^{[5]}$. Dexmedetomidine is a highly selective $\alpha 2$ adrenergic agonist with an affinity of eight times greater than clonidine. There is no such study which has compared the dose equivalence of these drugs but the observations of various studies have stated that the dose of clonidine is 1.5-2 times higher than dexmedetomidine when used in epidural route ${ }^{[6]}$. The anaesthetic and the analgesic requirement get reduced to a huge extent by the use of these two agents. The aim of this study is to compare dexmedetomidine and clonidine as an adjuvant to ropivacaine for epidural anaesthesia in lower abdominal and lower limb surgeries.

\section{Materials and Methods}

This study was carried out in the department of Anaesthesiology, Kakatiya Medical College, Mahatma Gandhi Memorial Hospital, from December 2016 to August 2017. The study was approved by the Hospital ethical committee. In this study 50 patients undergoing elective lower abdominal surgeries and lower limb surgeries, aged between 18-45 years of either gender, belonging to ASA grade I and II randomly divided into two groups by lottery method. After taking written informed consent from patients, they were subjected to epidural catheterization with 16 or $18 \mathrm{G}$ touhy`s needle and epidural anaesthesia given.
Group RC: This group comprises of patients in whom $19 \mathrm{ml}$ of $0.75 \%$ Ropivacaine with Inj. clonidine $2 \mu \mathrm{g} / \mathrm{kg}$ (made to $1 \mathrm{ml}$ ) administered epidurally.

Group RD: Consists of patients in whom $19 \mathrm{ml}$ of $0.75 \%$ Ropivacaine with inj. Dexmedetomidine $1.5 \mu \mathrm{g} / \mathrm{kg}$ (made to $1 \mathrm{ml}$ ) administered epidurally.

\section{Inclusion Criteria}

1. ASA grade I and II physical status,

2. Age between 18-45 years,

3. Patients belongs to both sexes undergoing lower abdominal and lower limb surgeries.

\section{Exclusion Criteria}

1. Patients not willing to participate in the study.

2. Patients with ASA grade III, IV\& V.

3. Those with known sensitivity to local anaesthetics.

4. Patients with local infection at the site of injection.

5. Uncooperative patient

\section{Statistical Data}

At the end of the study all the data is compiled and statistically analyzed using, Descriptive data presented as mean \pm SD. Continuous data analyzed by paired or unpaired " $\mathrm{t}$ " test. Chi - square test to analyze statistical difference between the two groups.

\section{Procedure}

During preoperative visit patient's detailed history, general physical examination and systemic examination were carried out. Basic demographic data like age, sex, height and weight were recorded. During pre-anaesthetic checkup the linear visual analogue scale (VAS) was explained to all patients using $10 \mathrm{~cm}$ scale. All the patients were premedicated with $0.05 \mathrm{mg} / \mathrm{kg}$ midazolam IM 1 hour prior to the procedure. The pulse rate, respiratory rate, blood pressure and $\mathrm{SpO} 2$ were recorded before starting the case. Peripheral venous cannulation was done with $18 \mathrm{G}$ IV cannula and all the patients were preloaded with $10 \mathrm{ml} / \mathrm{kg}$ Ringer Lactate solution.

Patients were placed in left lateral position and under strict aseptic precautions, after local infiltration with $1 \%$ Lignocaine hydrochloride the 
epidural space was identified with a 18/16G Tuohy needle at L3-L4 interspace, by "loss of resistance" technique. $18 / 16 \mathrm{G}$ epidural catheter was threaded through the needle in to the epidural space for 3$4 \mathrm{cms}$ and secured with adhesive tapes to the back. After negative aspiration for blood and CSF, $3 \mathrm{ml}$ of $2 \%$ Lignocaine with $15 \mu \mathrm{gm}$ of adrenaline was given as test dose and the patient was turned to supine position. After 5 minutes if there is no adverse reaction for the test dose, intravascular and intrathecal placement were ruled out and the study drugs were administered

Group RC, $\mathrm{n}=25$, were given $19 \mathrm{ml}$ of $0.75 \%$ Ropivacaine and Inj. Clonidine $2 \mu \mathrm{g} / \mathrm{kg}$ (made to $1 \mathrm{ml})$ epidurally.

Group RD, $\mathrm{n}=25$, were given $19 \mathrm{ml}$ of $0.75 \%$ Ropivacaine and inj. Dexmedetomidine $1.5 \mu \mathrm{g} / \mathrm{kg}$ (made to $1 \mathrm{ml}$ ) epidurally.

The level of sensory block was assessed by bilateral pinprick method, quality of motor blockade assessed by Bromage scale at 5, 10, 15, 20, 25, 30 minutes intervals. Time of injection was recorded as 0 hour. In the two groups:

onset of sensory blockade at T10 level, Maximum sensory level achieved, Onset of motor blockade, Two segment regression time, Duration of motor block, Duration of analgesia were recorded continuously $\mathrm{SpO} 2$, respiratory rate, heart rate, were monitored. Hemodynamic variables like systolic BP, diastolic BP, Mean Arterial Pressure, heart rate were recorded every 5 minutes until 30 minutes and at 15 minutes interval thereafter upto 90 minutes and then at 30 minutes interval till the end of surgery. Sedation scores were recorded just before the initiation of surgery and thereafter every 20 minutes during surgical procedure. Side effects like nausea, vomiting, bradycardia, hypotension, respiratory depression, dry mouth and shivering were noted in both groups.

Onset of sensory blockade- is taken from the completion of injection of study drug till the patient does not feel the pin prick. Onset of motor blockade- is taken from the completion of injection of study drug till the patient is unable to move feet. Duration of motor blockade- is taken from the completion of injection of study drug till motor block regresses to bromage scale 1. Duration of sensory block- is taken from the completion of injection of study drug till sensory block regression to T12 dermatomal level. Duration of analgesia - is taken from the completion of injection of study drug till the patient has VAS (Visual Analogue Scale) score $\geq 4$.

\section{Results}

The mean age of group RC was 33.8 years and mean age of group RD was 34.28 years, hence both group were comparable in regard to age. The mean weight of the group $\mathrm{RC}$ patients was $57.6 \mathrm{~kg}$ and group RD was $57.92 \mathrm{~kg}$. The difference in mean body weight between the two groups was statistically not significant. In group RC there were $56 \%$ males and $44 \%$ females and in group RD there were $52 \%$ males and $48 \%$ females. The difference in sex distribution between two groups was statistically not significant. The mean height of the group RC patients were 155.76 and in group RD was 154.32. The difference in height distribution between two groups was statistically not significant. The two groups were comparable with respect to age, weight, sex, height distribution.

The different types of surgeries conducted in the study were mentioned in table 1 . The sensory and motor anaesthetic parameters were shown in table 2 .

\section{Highest Sensory Level Achieved}

Out of 25 patients in group RC 4 patients achieved T4 level, 11 patients achieved T6 level and 10 patients T8 and in group RD 5 patients achieved T4, 11 patients achieved T6 and 9 patients achieved T8. The highest sensory level achieved in both groups were comparable and they are statistically not significant ( $\mathrm{p}>0.05)$

Table 1: Types of surgery in both groups

\begin{tabular}{|l|c|c|}
\hline Type of Surgery & Group RC & Group RD \\
\hline Hernioplasty & 7 & 7 \\
\hline Lower Limb & 5 & 4 \\
\hline TAH & 4 & 5 \\
\hline Ovariotomy & 3 & 4 \\
\hline Appendicectomy & 6 & 5 \\
\hline Total: & 25 & 25 \\
\hline
\end{tabular}


Table 2: Anaesthetic parameters in both groups

\begin{tabular}{|l|c|c|c|}
\hline $\begin{array}{l}\text { Time in } \\
\text { minutes }\end{array}$ & $\mathrm{RC}$ & $\mathrm{RD}$ & $\mathrm{P}$ value \\
\hline $\begin{array}{l}\text { onset of } \\
\text { sensory block }\end{array}$ & $9.5 \pm 1.69$ & $7.92 \pm 1.63$ & $0.0015^{*}$ \\
\hline $\begin{array}{l}\text { time to achieve } \\
\text { maximum } \\
\text { sensory level }\end{array}$ & $14.32 \pm 2.39$ & $12 \pm 2.68$ & $0.0022^{*}$ \\
\hline $\begin{array}{l}\text { onset of motor } \\
\text { blockade }\end{array}$ & $20.76 \pm 2.89$ & $18.68 \pm 2.56$ & $0.0097^{*}$ \\
\hline $\begin{array}{l}\text { two segment } \\
\text { regression time }\end{array}$ & $142.8 \pm 10.32$ & $124 \pm 10.61$ & $0.0001^{*}$ \\
\hline $\begin{array}{l}\text { duration of } \\
\text { motor blockade }\end{array}$ & $228.6 \pm 26.44$ & $252.40 \pm 28.45$ & $0.0356^{*}$ \\
\hline $\begin{array}{l}\text { duration of } \\
\text { analgesia }\end{array}$ & $308.8 \pm 40.01$ & $395.6 \pm 58.12$ & $0.0001^{*}$ \\
\hline
\end{tabular}

\section{Haemodynamic changes}

The systolic, diastolic, mean arterial pressures in both groups were mentioned in fig 1,2\&3 and mean heat rate during the epidural anaesthesia was shown in fig.4. These were noticed at $0,5,10,15,20,25,30$, $45,60,75,90$ and $120 \mathrm{~min}$ mentioned as 1-12 numbers respectively in graph.

Fig.1 Systolic Blood Pressure among Both Groups

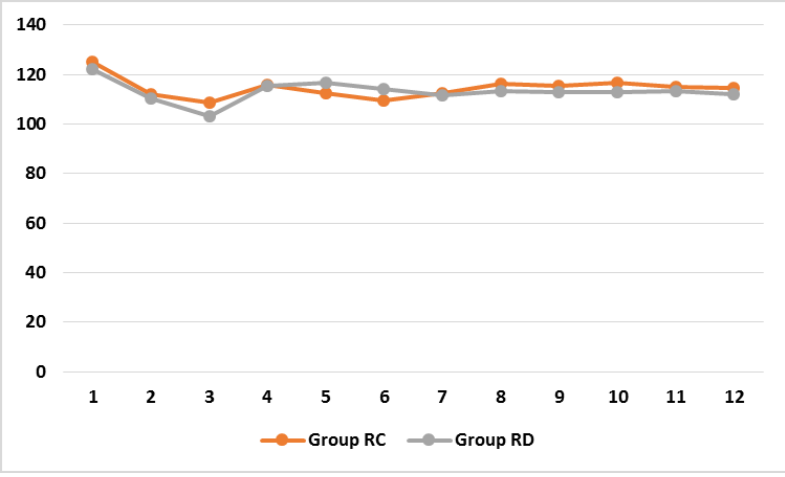

Fig 2 Diastolic Blood Pressure among Both Groups

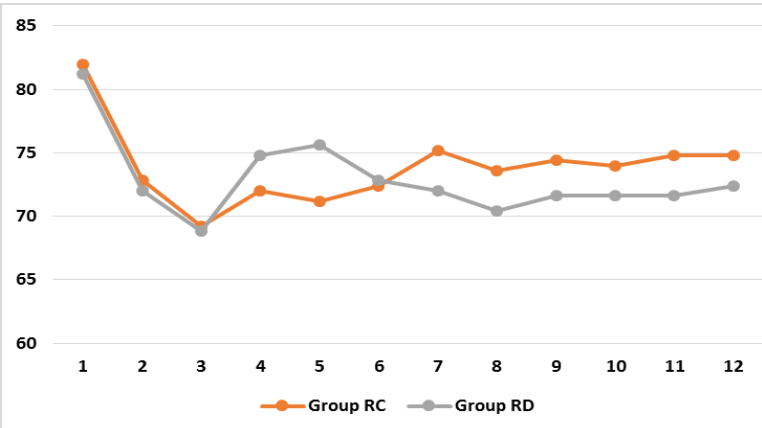

Fig.3: Mean arterial blood pressure

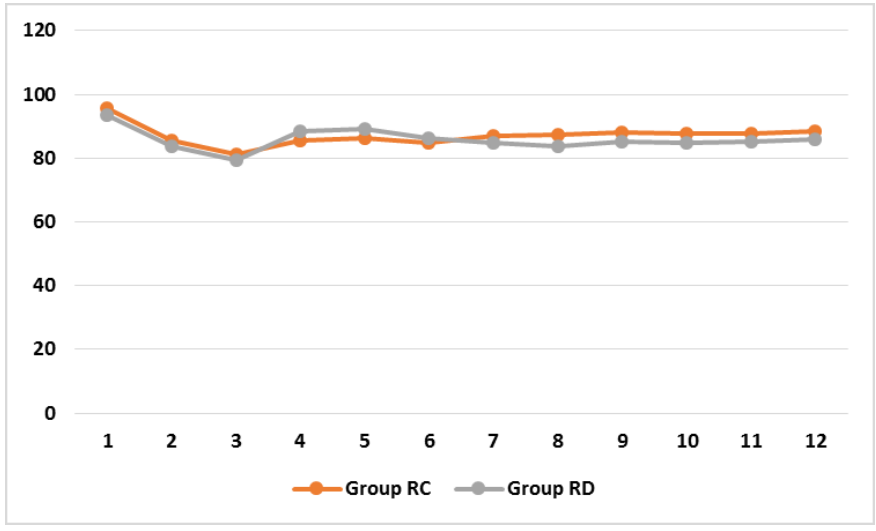

Fig .4 Heart Rate Variation among Both Groups

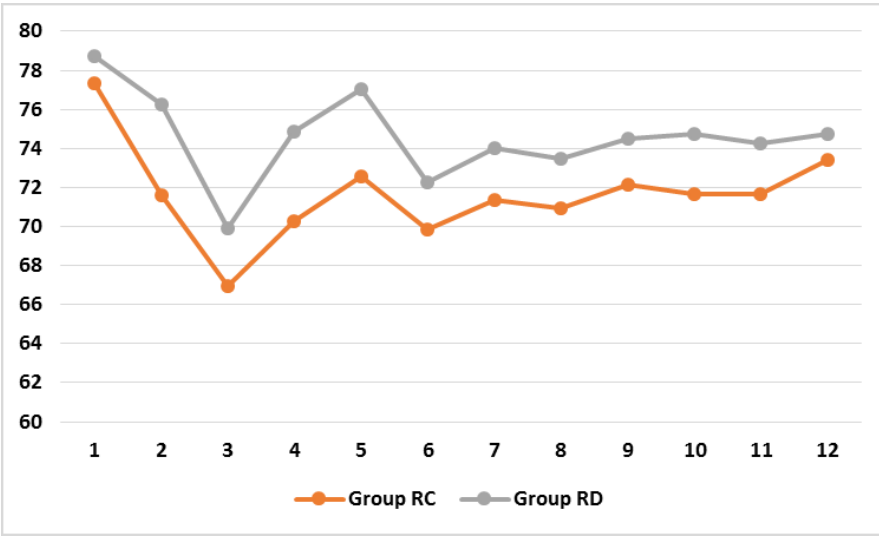

Table 3: Sedation Score among Both Groups

\begin{tabular}{|l|c|c|c|}
\hline $\begin{array}{l}\text { Sedation } \\
\text { Score }\end{array}$ & Group RC & Group RD & p-Value \\
\hline 1 & $13(52 \%)$ & $4(16 \%)$ & $<0.0001$ \\
\hline 2 & $4(16 \%)$ & $5(20 \%)$ & 0.5813 \\
\hline 3 & $8(32 \%)$ & $16(64 \%)$ & $<0.0001$ \\
\hline 4 & 0 & 0 & - \\
\hline 5 & 0 & 0 & - \\
\hline
\end{tabular}

\section{Side Effects}

In our study $20 \%(\mathrm{n}=5)$ of patients in group $\mathrm{RC}$, $16 \%(n=4)$ in group RD had bradycardia. $24 \%(n=6)$ of patients in group RC, $32 \%(\mathrm{n}=8)$ in group $\mathrm{RD}$ had hypotension. $16 \%(n=4)$ of patients in both the groups had nausea, $4 \%(n=1)$ in both the groups had vomiting. $24 \%(\mathrm{n}=6)$ of patients in group $\mathrm{RC}, 20 \%$ $(n=5)$ in group RD had dry mouth. The occurrence of these side effects are statistically not significant.

\section{Discussion}

The use of neuraxial opioids is associated with few side effects, so various options including $\alpha-2$ agonists are being extensively evaluated as an alternative with emphasis on opioid-related side 
effects such as respiratory depression, nausea, urinary retention and pruritis. Epidural administration of these drugs is associated with sedation, analgesia, anxiolysis, hypnosis and sympatholysis. Clonidine has been used successfully over the last decade for the said purpose and the introduction of dexmedetomidine has further widened the scope of $\alpha-2$ agonists in regional anaesthesia. The faster onset of action of local anaesthetics, rapid establishment of both sensory and motor blockade, prolonged duration of analgesia into the post-operative period, dosesparing action of local anaesthetics and stable cardiovascular parameters makes these agents a very effective adjuvant in regional anaesthesia.

\section{Onset of sensory blockade}

In our study the mean time of onset of sensory blockade at T10 in Group RD was significantly less than Group RC (Group RD $7.92 \pm 1.63 \mathrm{~min}$, Group RC $9.5 \pm 1.69 \mathrm{~min}, \mathrm{P}<0.05)$. In a study conducted by Sukhminder Jit Singh et $\mathrm{al}^{[7]}$, Addition of dexmedetomidine to ropivacaine as an adjuvant resulted in an earlier onset (8.52 \pm 2.36 minutes) of sensory analgesia at $\mathrm{T} 10$ as compared to the addition of clonidine $(9.72 \pm 3.44$ minutes $)$. Study conducted by Soni et al $^{[8]}$ comparative study for better adjuvant with ropivacaine in epidural anaesthesia, the mean onset of sensory block was $5.7+2.0 \mathrm{~min}$ for dexmedetomidine and $(9.6 \pm 2.9)$ minutes for clonidine, which is significant. Our results are concurring with the above studies.

\section{Time to achieve maximum sensory level}

In our study the mean time to achieve maximum sensory level was significantly less in group RD compared to group RC ( $12 \pm 2.68$ minutes for group $\mathrm{RD}, 14.32 \pm 2.39$ minutes for group $\mathrm{RC}, \mathrm{P}<0.05$ ) Arun Kumar et al. ${ }^{[9]}$ conducted study on dexmedetomidine and clonidine as an adjuvant to Ropivacaine for epidural anaesthesia in lower abdominal and lower limb surgeries- concluded that time to achieve maximum sensory level was faster in group RD compared to group RC. Sravana babu et al. ${ }^{[10]}$ conducted study on dexmedetomidine and clonidine as adjuvant to Ropivacaine in epidural anaesthesia for post-operative analgesia in spine surgeries. The mean time to achieve maximum sensory level in group RC was $13.20 \pm 2.90$, in group RD was $11.66 \pm 2.05$ which is statistically significant $(\mathrm{p}<0.05)$ Our results are concurring with above studies

\section{Time for Complete Motor Blockade}

In our study the mean time to onset of motor blockade in group RD was significantly less compared to group $\mathrm{RC}(18.68 \pm 2.56$ minutes in group $\mathrm{RD}, 20.76 \pm 2.89$ minutes in group $\mathrm{RC}$, $\mathrm{p}<0.05)$ In contrast to our study Arun kumar et al. ${ }^{[9]}$ found that no statistically significant time to complete motor blockade between two group RD it was $23.00 \pm 4.27$ and in group RC it was $23.07 \pm$ 4.63 minutes. In a study of Shaikh and Sarala et al, ${ }^{[11]}$ showed Motor block of Bromage 3 was achieved earlier in patients from the dexmedetomidine group $(19.30 \pm 1.62)$ than of the clonidine (19.30 \pm 1.62$)$ group.

\section{Two Segment Regression Time}

In our study the two segment regression time in Group RD was significantly higher than Group RC in Group RD was $142.8 \pm 10.32$ minutes, in group $\mathrm{RC}$ was $124 \pm 10.61$ minutes)In a study conducted by Shaikh and sarala et al, ${ }^{[1]}$ In dexmedetomidine group, time for two segment regression $(136 \pm 6.86)$ was prolonged when compared to clonidine group $(124.97 \pm 6.65)$. According to Alves $\mathrm{TC}$ et $\mathrm{al}^{[12]}$, epidural Clonidine with Ropivacaine significantly prolonged sensory, motor and post-operative analgesia, when compared to plain Ropivacaine alone. Our results are concurring with above studies.

\section{Duration of Motor Blockade}

Our study also showed that duration of motor block was significantly prolonged in group RD compared to group RC [252.40 \pm 28.45 minutes ( 4.2 hours) Vs $228.6 \pm 26.44$ minutes ( 3.8 hours), $\mathrm{p}<0.05$ ]. 


\section{Duration of Analgesia}

In our study duration of analgesia in group RD was $395.6 \pm 58.12$ minutes, (6.58 hours) compared to group RC $308.8 \pm 40.01$ minutes ( 5.13 hours). It is statistically very significant as $p<0.0001$. In a study conducted by A.M. Abd-Elwahab et al, ${ }^{[13]}$ Addition of dexmedetomidine or clonidine to caudal bupivacaine significantly promoted analgesia. Both drugs were comparable as regards the analgesia duration. Salgado PF et al ${ }^{[14]}$ showed that there is clear synergism between epidural dexmedetomidine and ropivacaine, prolonged sensory and motor block duration time ( $\mathrm{p}<0.05)$ and postoperative analgesia ( $\mathrm{p}<0.05)$, and also resulted in a more intense motor block.

\section{Hemodynamic Parameters}

In our study the following hemoodynamcis like systolic blood pressure, diastolic blood pressure, mean arterial pressure, heart rate were monitored in both the groups. These parameters were monitored at $0,5,10,15,20,25,30$ minutes and every 15 minutes there after upto 120 minutes.

Hemodynamic variables SBP, DBP, MAP and heart rate are comparable in both the groups. Arun kumar et $\mathrm{al}^{[9]}$ observed that HR significantly fell in both groups by $20 \%$ in $30-50$ minutes after the epidural injection and blood pressure decreased by $25 \%$ in 30-50 minutes following epidural injection.

However this change was not statistically significant.

\section{Mean Sedation Score}

Grading of sedation was evaluated by a Wilson's sedation scale. $13(52 \%)$ and $4(16 \%)$ graded as 1,4 $(16 \%)$ and $5(20 \%)$ graded as 2, $8(32 \%)$ and 16 (64\%) graded as 3, in group RC and RD respectively. None of the patients graded as 4 or 5 in either group. a study done by Bajwa et al, ${ }^{[7]}$ also showed a significantly higher level of sedation in the patients, who received dexmedetomidine in comparison to clonidine. In a similar study conducted by shaikh and sarala et al. ${ }^{[1]}$ who compared bupivacaine with clonidine and dexmedetomidine epidurally, patients in both the groups are remained calm throughout surgery but mean sedation score were significantly higher in the dexmedetomidine group compared to clonidine group $(\mathrm{P}<$ 0.0001). Sedation scores were statistically significant at 20 minutes, 40 minutes, and 60 minutes in group A (dexmedetomidine) compared to group B (clonidine). These findings from the studies mentioned above concur from our study, showing that dexmedetomidine causes significant higher sedation than clonidine when given epidurally. None of the patients in two groups had any other side effects like respiratory depression, shivering etc.

\section{Conclusion}

We conclude that dexmedetomidine is a better adjuvant than clonidine in epidural anaesthesia as far as patient comfort, stable cardio-respiratory parameters, intra-operative and post-operative analgesia is concerned. Overall the experience with dexmedetomidine was quite satisfactory as compared to clonidine because of its superior sedative and anxiolytic properties during the surgical procedure under regional anaesthesia.

\section{References}

1. Höhener D, Blumenthal S, Borgeat A. Sedation and regional anaesthesia in the adult patient. Br J Anaesth 2008;100:8-16.

2. Helgeson LE. Sedation during regional anaesthesia: Inhalational versus intravenous. Curr Opin Anaesthesiol 2005;18:534-9.

3. Asehnoune K, Albaladejo P, Smail N, Heriche C, Sitbon P, Gueneron JP, et al. Information and anaesthesia: What does the patient desire? Ann Fr Anesth Reanim 2000;19:577-81.

4. Schnider TW, Minto CF. Predictors of onset and offset of drug effect. Eur J Anaesthesiol 2001;23:26-31.

5. Mauro VA, Brandão ST. Clonidine and dexmedetomidine through epidural route for post-operative analgesia and sedation in a cholecystectomy. Rev Bras Anestesiol 2004;4:1-10. 
6. Schnaider TB, Vieira AM, Brandão AC, Lobo MV. Intra-operative analgesic effect of cetamine, clonidine and dexmedetomidine, administered through epidural route in surgery of the upper abdomen. Rev Bras Anestesiol 2005;55:525-31.

7. Sukhminder Jit Singh Bajwa, Sukhwinder Kaur Bajwa, Jasbir Kaur, Gurpreet Singh, vikramjit Aroral, Sachin Gupta, Ashish Kulshrestha, Amarjit Singh, SSParmar, AnithaSingh, SPSGoraya. Dexmedetomidine and clonidine in epidural anaesthesia: A comparative evaluation -- Indian Journal of Anaesthesia, 2011 | Volume: 55 | issue: 2 | Page: 116-121.

8. Pramila Soni. Comparison study for better adjuvant with ropivacaine in epidural anaesthesia-, anaesthesia essays and researches 2016 may-aug 10 (2)218-222.

9. Sruthi arun kumar, V. Hemanth kumar, N. Krishnaveni, M. Ravi shanker, Velraj jaya and M. Aruloli. Comparison of dexmedetomidine and clonidine as adjuvant ropivacaine for epidural anaesthesia in lower limb and lower abdominal surgeries- Saudi Journal of Anaesthesia, 2015 | oct -dec 9(4) 404-408.

10. MS Sravana babu,Anil kumar verma, Apurva agarwal, Chitra MS thyagi, Manoj upodhyay and Shiv shanker tripati Comparative study in the post-operative spine surgeries epidural ropivacaine with dexmedetomidine and ropivacaine with clonidine for post-operative analgesia Indian Journal of Anaesthesia 2013 july-aug 57(4) 317-376.

11. Safiya, Shaikh, Sarala, B. Mahesh. The efficacy and safety of epidural dexmedetomidine and clonidine with bupivacaine in patients undergoing lower limb orthopedic surgeries - Journal Of Anaesthesiology Clinical Pharmacology 2016 Apr- Jun v 32(2) 203- 209.
12. F.W.Abdallah et al. Facilitatory effects of perineural dexmedetomidine on neuraxial and peripheral nerve block: a systematic review Br. J. Anaesth. (2013) doi: 10.1093/bja/aet066.

13. A.M. Abd-Elwahab, A.M. AbdElmaksound, A.M. El-hennawy, H.S.ElOzairy, S.R. Boulis. Addition of clonidine or dexmedetomidine to bupivacaine prolongs caudal analgesia in children, Br. J. Anaesth. (2009) 103 (2): 268-274.

14. Salgado PF, Sabbag AT, Silva PC, Brienze SL, Dalto HP, Módolo NS, Braz JR, Nascimento P Jr. Hospital de Base da Faculdade de Medicina de São José do Rio Preto, SP-Synergistic effect between dexmedetomidine and $0.75 \%$ ropivacaine in epidural anesthesia -- Rev Assoc Med Bras. 2008 Mar-Apr;54(2):110-5. 